\title{
RISK OF TYPE 2 DIABETES MELLITUS IN PATIENTS WITH HEPATITIS C INFECTION.
}

\footnotetext{
1. MBBS, FCPS

Associate Professor

Department of Medical Unit-II Civil Hospital

Dow University Health Sciences Karachi.

2. MBBS, FCPS

Consultant Physician Department of Medical OPD Civil Hospital Karachi.

3. MBBS, FCPS

Emergency Medical Specialist

Remedial Centre, North Nazimabad.

Correspondence Address:

Dr. Darshan Kumar

Department of Medical Unit-II

Civil Hospital

Dow University Health Sciences

Karachi.

darshankumardow@gmail.com
}

Article received on:

17/10/2018

Accepted for publication:

10/04/2019

Received after proof reading:

25/06/2019

\begin{abstract}
Darshan Kumar ${ }^{1}$, Nuzhat Parven ${ }^{2}$, Jawahar Lal ${ }^{3}$
ABSTRACT... The objective of this study is to Hepatitis C Infection patients leads to type 2 diabetes mellitus. Study Design: Cross sectional study. Setting: Civil hospital, Karachi. Period: June 2017 to February 2018. Materials and Methods: We screened 1941 patients and out of them 328 patients had HCV positive serology. HCV serology status was assessed by checking for HCV antibody. To evaluate incidence of type 2 diabetes mellitus in patients with HCV seropositivity, blood glucose levels of all patients were performed. Patients with cirrhosis, pancreatitis, co-existent hepatitis $\mathrm{B}$ and any other co-morbid. According to new diagnostic criteria by WHO hyperglycaemia is labelled at blood glucose levels of $200 \mathrm{mg} / \mathrm{dl}$. Results: We found total 328 cases showing HCV seropositivity out of total 1941 patients visiting the outpatient department. There were 213 males and 115 females in the data. The demographic data of patients suggests that $53 \%$ patients lived in rural areas whereas $47 \%$ had their residence in urban areas. This suggests that patients living in rural areas having slightly higher prevalence of hepatitis $C$ than those in urban areas It suggests that age group 30-40 had highest prevalence of hepatitis $C$ and age 50-60 had lowest prevalence of hepatitis C. Out of $328,36 \%(n=118)$ patients had developed diabetes mellitus. The viral load of patients was also performed, and it was found to be in the range of 1567 to $8706576 \mathrm{IU} / \mathrm{ml}$ in males. In females it was 1340 to $6890042 \mathrm{IU} / \mathrm{ml}$. The results revealed that males have higher viral load than females. Conclusion: In patients with HCV infection, there is increased risk of development of type 2 diabetes mellitus. Glucose metabolism abnormalities start a lot earlier than systemic manifestations of hepatitis C. So, blood glucose levels should be regularly checked to prevent complications. Hepatitis C should be treated at its earliest to help patients achieve improved glycaemic control.
\end{abstract}

Key words: $\quad$ BMI, Cirrhosis, Hepatitis C Infection, Hyperglycaemia Type 2 Diabetes Mellitus.

Article Citation: Kumar D, Parven N, Lal J. Risk of type 2 diabetes mellitus in patients with hepatitis c infection. Professional Med J 2019; 26(7):1005-1008.

DOI: 10.29309/TPMJ/2019.26.07.218

\section{INTRODUCTION}

Hepatitis C infection globally affects 180 million every year and is a major cause of cirrhosis, liver cancer and death. In the western world it is leading to increased liver transplantation procedures. There are total six genotypes of the virus, genotype 1 being associated with majority of cases. After introduction of infection, the body's immune system determines its eradication or persistence. Approximately $15-30 \%$ of patients with HCV infection progress to cirrhosis, it also depends upon the genotype infected. ${ }^{1}$ Various studies have been done to find the association between HCV infection and type 2 diabetes mellitus, chronic $\mathrm{HCV}$ infection increases the risk of developing diabetes mellitus up to 11-fold. Numerous other risk factors also predispose a person to develop type 2 diabetes mellitus like obesity, metabolic syndromes. ${ }^{2}$ Type 2 diabetes mellitus is the sixth leading cause of death, around 5.2 million people are expected to have undiagnosed diabetes. With these statistics and correlation, treating HCV infection is the most strategic step. As calculated, the standardized mortality ratio for cirrhosis is 2.52 , where as for cardiovascular diseases it is 1.34. HCV infection induces insulin resistance which leads to development of diabetes. This theory has been widely supported by longitudinal studies that insulin resistance is the best predictor for development of diabetes. ${ }^{3}$ Hepatitis C infection associated with diabetes mellitus causes increased fibrosis and decompensated 
cirrhosis. ${ }^{4}$ Insulin resistance is induced by the $\mathrm{HCV}$ core protein itself, it also depends upon the degree of liver involvement and the genotype. ${ }^{5}$ $\mathrm{HCV}$ proteins induce the formation of cytokines IL-6 and TNF-alpha, these cytokines promotes gluconeogenesis and fat accumulation into the liver. All these findings suggest the hypothesis that $\mathrm{HCV}$ infection treatment would improve glucose metabolism and decrease insulin resistance. ${ }^{6}$ Evidence for this hypothesis has been shown in various by checking pre and post treatment oral glucose tolerance test and HbA1c levels. With the onset of cirrhosis in HCV infection, insulin secretion is reduced. Insulin mediated glucose uptake by the cells is decreased by $50 \%$ in patients with cirrhosis. ${ }^{7}$ As the incidence of type 2 diabetes mellitus is higher in patients with $\mathrm{HCV}$, the presence of HCV antibodies is also higher in diabetic patients. With HCV infection there is $21 \%$ risk of development of diabetes as compared to HBV infection which has $10 \%$ risk. $^{8}$ With all these associations, patients with type 2 diabetes mellitus and constantly elevated serum ALT should be investigated for HCV markers. There is no need for alteration in drug therapy in patients with HCV infection, until the patient develops decompensated cirrhosis. Liver failure alters the metabolism of anti-hyperglycaemic drugs and necessitates dosage alterations. ${ }^{9}$ Our study aims to assess the incidence of diabetes mellitus in patients with $\mathrm{HCV}$ infection.

\section{METHOD}

This study had been conducted in Civil hospital, Karachi during the time June 2017 to February 2018. We selected patients visiting the medical outpatient department and started screening for hepatitis C virus infection. We screened 1941 patients and out of them 328 patients had HCV positive serology. HCV serology status was assessed by checking for HCV antibody. To evaluate incidence of type 2 diabetes mellitus in patients with HCV seropositivity, blood glucose levels of all patients were performed. The demographic data of patients like name, age, area of residence was also collected. Patients with cirrhosis, pancreatitis, co-existent hepatitis $B$ and any other co-morbid. According to new diagnostic criteria by WHO hyperglycaemia is labelled at blood glucose levels of $200 \mathrm{mg} / \mathrm{dl} .{ }^{10}$ Along with above investigations, viral load of patients was also performed.

\section{RESULTS}

We found total 328 cases showing HCV seropositivity out of total 1941 patients visiting the outpatient department. There were 213 males and 115 females in the data. The mean age of patients was found to be $38.4+6.53$ years. Patients were divided into age groups to identify which age group has greatest prevalence of incidence of hepatitis $\mathrm{C}$. the demographic data of patients suggests that $53 \%$ patients lived in rural areas whereas $47 \%$ had their residence in urban areas. This suggests that patients living in rural areas having slightly higher prevalence of hepatitis $C$ than those in urban areas. Table-I shows prevalence of hepatitis $C$ in different age groups. It suggests that age group 30-40 had highest prevalence of hepatitis $C$ and age 50-60 had lowest prevalence of hepatitis $C$.

All these patients were screened for hyperglycaemia by checking blood sugar levels. Type 2 diabetes mellitus was diagnosed when patient had blood glucose level of $>200 \mathrm{mg} / \mathrm{dl}$. Out of $328,36 \%(n=118)$ patients had developed diabetes mellitus. The viral load of patients was also performed, and it was found to be in the range of 1567 to $8706576 \mathrm{IU} / \mathrm{ml}$ in males. in females it was 1340 to $6890042 \mathrm{IU} / \mathrm{ml}$. The results revealed that males have higher viral load than females. Table-II shows BMl of patients. It shows that majority of patients with HCV infection have $\mathrm{BMI}$ in the range of 20-30. Obesity is also found to be associated with $\mathrm{HCV}$ infection.

\begin{tabular}{|c|c|}
\hline Age Group & Frequency (n) \\
\hline $20-30$ & 69 \\
\hline $30-40$ & 127 \\
\hline $40-50$ & 92 \\
\hline $50-60$ & 42 \\
\hline
\end{tabular}

Table-I. Prevalence of hepatitis $\mathrm{c}$ in different age groups

\begin{tabular}{|l|c|}
\hline \multicolumn{1}{|c|}{ BMI $\left(\mathbf{k g} / \mathbf{m}^{2}\right)$} & Frequency $\mathbf{( n )}$ \\
\hline$<20$ & 58 \\
\hline $20-30$ & 195 \\
\hline $30-40$ & 75 \\
\hline
\end{tabular}

Table-II. BMI of patients 


\section{DISCUSSION}

One of the very first multivariate analysis conducted in HCV patients showed that three-fold increase in glucose metabolism abnormalities. These evidences suggest that metabolic changes favouring development of diabetes start at early stages of diabetes. In HCV infected subjects, patients with normal transaminases have fivefold higher prevalence of diabetes so emphasis should be made for regular assessment of blood glucose levels. HCV has been recognized worldwide as a major cause of chronic liver disease worldwide and morbidity and mortality. ${ }^{11}$ The median duration from infection to chronic liver disease is 25 years, whereas in women less than $30 \%$ of infected women progress to chronic liver disease. ${ }^{12}$ Individuals with potential risk factors should be tested for $\mathrm{HCV}$, so that treatment should be initiated as early as possible. Previous studies suggest that early development of insulin resistance and diabetes mellitus favours screening of blood glucose levels regularly with $\mathrm{HCV}$ infection.

Further studies suggests that in patients with chronic hepatitis OGTT should be recommended as the primary screening test for diabetes ${ }^{13}$ Either $\mathrm{HCV}$ infection is the cause of diabetes or diabetic subjects are more prone to get HCV infection is still debatable. There are still no proven epidemiological or etiological factor for acquiring HCV infection in diabetic subjects. ${ }^{14}$ There is higher prevalence of abnormal LFTs due to fatty infiltration of liver in diabetic patients. Risk factors for HCV infection like age, previous blood and other blood products transfusion and intravenous drug abuse have higher risk ratio in diabetes. We also identified that patients were referred to our unit for diabetes and abnormal LFTs, so HCV markers testing should be mandatory in these patients. ${ }^{13}$ The primary treatment modality for hepatitis $C$ is interferon-alpha or directly acting antiviral agents. There has been found to be increase in autoimmune phenomenon in patients treated with interferon-alpha for infections or neoplasms..$^{15}$ The higher prevalence of diabetes in $\mathrm{HCV}$ infection is not associated with risk factors as the same factors are also associated with hepatitis $B$. Hepatitis B infection is not associated with development of type 2 diabetes mellitus as is hepatitis $\mathrm{C} .{ }^{16} \mathrm{~A}$ research done revealed that $52 \%$ of patients with HCV infection and diabetes had blood transfusions 10-20 years before their diagnosis of diabetes mellitus. ${ }^{13}$ Patients with HCV positive serology have abnormal LFTs in around $72.3 \%$ of patients. Most common pattern of LFTs is combination of eytolysis and cholestasis. ${ }^{17}$ There has been no association between the genotype of HCV and cirrhosis. The only finding is that there is lower prevalence of cirrhosis associated with genotype 3 due to younger age group. ${ }^{18}$

\section{CONCLSION}

In patients with $\mathrm{HCV}$ infection, there is increased risk of development of type 2 diabetes mellitus. Glucose metabolism abnormalities start a lot earlier than systemic manifestations of hepatitis C. So, blood glucose levels should be regularly checked to prevent complications. Hepatitis C should be treated at its earliest to help patients achieve improved glycemic control.

\section{Copyright $\odot 10$ Apr, 2019.}

\section{REFERENCES}

1. Rosen HR. Chronic hepatitis $\mathbf{C}$ infection. New England Journal of Medicine. 2011; 364(25):2429-38.

2. Antonelli A, Ferrari SM, Giuggioli D, Di Domenicantonio A, Ruffilli I, Corrado A, et al. Hepatitis C virus infection and type 1 and type 2 diabetes mellitus. World journal of diabetes. 2014; 5(5):586.

3. Ortiz V, Berenguer M, Rayón JM, Carrasco D, Berenguer Jn. Contribution of obesity to hepatitis C-related fibrosis progression. The American journal of gastroenterology. 2002; 97(9):2408-14.

4. Monto A, Alonzo J, Watson JJ, Grunfeld C, Wright TL. Steatosis in chronic hepatitis C: Relative contributions of obesity, diabetes mellitus, and alcohol. Hepatology. 2002; 36(3):729-36.

5. Miyamoto H, Moriishi K, Moriya K, Murata S, Tanaka K, Suzuki T, et al. Involvement of the PA28y-dependent pathway in insulin resistance induced by hepatitis C virus core protein. Journal of virology. 2007; 81(4):1727-35.

6. Delgado-Borrego A, Jordan SH, Negre B, Healey $D$, Lin W, Kamegaya $Y$, et al. Reduction of insulin resistance with effective clearance of hepatitis $C$ infection: Results from the HALT-C trial. Clinical Gastroenterology and Hepatology. 2010; 8(5):458-62. 
7. Knowler WC, Barrett-Connor E, Fowler SE, Hamman RF, Lachin JM, Walker EA, et al. Reduction in the incidence of type 2 diabetes with lifestyle intervention or metformin. The New England journal of medicine. 2002; 346(6):393-403.

8. Hourigan LF, Macdonald GA, Purdie D, Whitehall VH, Shorthouse C, Clouston A, et al. Fibrosis in chronic hepatitis $\mathbf{C}$ correlates significantly with body mass index and steatosis. Hepatology. 1999; 29(4):1215-9.

9. Mehta SH, Brancati FL, Sulkowski MS, Strathdee SA, Szklo M, Thomas DL. Prevalence of type 2 diabetes mellitus among persons with hepatitis $\mathrm{C}$ virus infection in the United States. Annals of internal medicine. 2000; 133(8):592-9.

10. Care D. Type 2 diabetes worldwide according to the new classification and criteria. Diabetes care. 2000; 23(2):B5-B10.

11. Organization WH. Global surveillance and control of hepatitis C. Report of a WHO Consultation organized in collaboration with the Viral Hepatitis Prevention Board, Antwerp, Belgium. J Viral Hepat. 1999; 6:35-47.

12. Salomon JA, Weinstein MC, Hammitt JK, Goldie SJ. Empirically calibrated model of hepatitis $C$ virus infection in the United States. American journal of epidemiology. 2002; 156(8):761-73.
13. Mehta SH, Brancati FL, Sulkowski MS, Strathdee SA, Szklo M, Thomas DL. Prevalence of type 2 diabetes mellitus among persons with hepatitis $\mathbf{C}$ virus infection in the United States. Hepatology. 2001; 33(6):1554-.

14. Knobler $H$, Schihmanter $R$, Zifroni A, Fenakel G, Schattner $A$, editors. Increased risk of type 2 diabetes in noncirrhotic patients with chronic hepatitis $\mathbf{C}$ virus infection. Mayo Clinic Proceedings; 2000: Elsevier.

15. Kozbial K, Moser S, Al $\square$ Zoairy R, Schwarzer R, Datz C, Stauber $\mathrm{R}$, et al. Follow $\square$ up of sustained virological responders with hepatitis $\mathbf{C}$ and advanced liver disease after interferon/ribavirin $\square$ free treatment. Liver International. 2018; 38(6):1028-35.

16. Okan V, Araz M, Aktaran S, Karsligil T, Meram I, Bayraktaroglu Z, et al. Increased frequency of HCV but not HBV infection in type 2 diabetic patients in Turkey. International journal of clinical practice. 2002; 56(3):175-7.

17. Lee $\mathrm{MH}$, Yang HI, Yuan Y, L'Italien G, Chen C-J. Epidemiology and natural history of hepatitis $\mathbf{C}$ virus infection. World journal of gastroenterology: WJG. 2014; 20(28):9270.

18. Lecube A, Hernández C, Genescà J, Esteban JI, Jardí $R$, Simó R. High prevalence of glucose abnormalities in patients with hepatitis $C$ virus infection: $A$ multivariate analysis considering the liver injury. Diabetes care. 2004; 27(5):1171-5.

\begin{tabular}{|c|l|l|l|}
\hline \multicolumn{3}{|c|}{ AUTHORSHIP AND CONTRIBUTION DECLARATION } \\
\hline Sr. \# & Author-s Full Name & \multicolumn{1}{|c|}{ Contribution to the paper } & Author=s Signature \\
\hline 1 & Darshan Kumar & $\begin{array}{l}\text { Concept and design, Statistical } \\
\text { expertise, Critical revision of the } \\
\text { article for important intellectual } \\
\text { content. } \\
\text { Data collection, Critical revision of } \\
\text { the article for important intellectual } \\
\text { content. } \\
\text { Drafting of the article. }\end{array}$ \\
\hline 3 & Jawahar Lal & Nuzhat Parven & \\
\hline
\end{tabular}

